\title{
STRENGTH BALANCE OF STEEL DAMPER COLUMNS AND SURROUNDING BEAMS IN REINFORCED CONCRETE FRAMES
}

\author{
KENJI FUJII \& MIZUKI KATO \\ Department of Architecture, Chiba Institute of Technology, Japan
}

\begin{abstract}
In earthquake-prone countries, energy dissipated devices (dampers) have recently been widely used in building structures. Their main purpose is to mitigate damage to beams and columns during strong seismic events. The dampers act as energy absorbing members. In this study, the strength balance of steel damper columns and surrounding beams contained in reinforced concrete frames is investigated. First, the damper column strength ratio is defined on the basis of the rigid-perfectly plastic mechanical model. Next, a nonlinear dynamic analysis of various frame models was performed to investigate the influence of the damper column strength ratio on the nonlinear seismic response of reinforced concrete frames containing steel damper columns. The results of the analysis indicate that that the proper strength balance of the steel damper columns and surrounding beams is important in maximizing the energy dissipation into the damper columns. The beam-end section connected to the damper columns needs sufficient strength to avoid premature yielding prior to any energy dissipation. To discuss the strength balance of steel damper columns and surrounding beams, the damper column strength ratio is a possible index.

Keywords: steel damper column, reinforced concrete frame, energy dissipation, damper column strength ratio.
\end{abstract}

\section{INTRODUCTION}

The steel damper column is one energy dissipating device (damper) used to control seismic damage in building structures [1], [2]. Fig. 1 illustrates a steel damper column and its application in a reinforced concrete (RC) frame structure. In the steel damper column (Fig. 1(a)), low-yield-strength steel is used in shear panel dampers, which absorb the hysteresis energy [1], [2].

Steel damper columns are installed in the mid-span of RC beams (Fig. 1(b)). The deformation of a shear damper panel (Fig. 1(a)) is influenced not only by the deformation of the roll-formed H-section column (elastic column), but also the deformation of the RC beams connected to the damper column. The main purpose of these dampers is to minimize the damage to beams and columns caused by strong seismic displacements. Using dampers enables the energy to be absorbed. Because the shear damper panel begins to absorb hysteresis energy when it yields, the effectiveness of the damper column depends strongly on the strength balance of the damper columns and their surrounding RC members. In addition, the yield strength of the damper panel increases through strain hardening [1]-[3]. Therefore, strain hardening should be considered when evaluating strength balance. On the basis of these discussions, two questions arise:

- What kind of index is appropriate to evaluate quantitatively the strength balance of steel damper columns and surrounding RC beams?

- What criterion, based on the strength balance, holds for steel damper columns to be effective? 


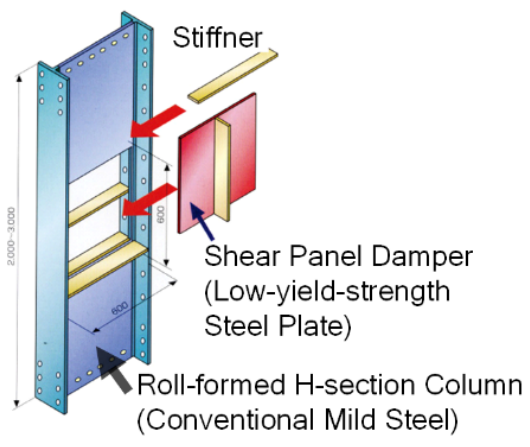

(a)

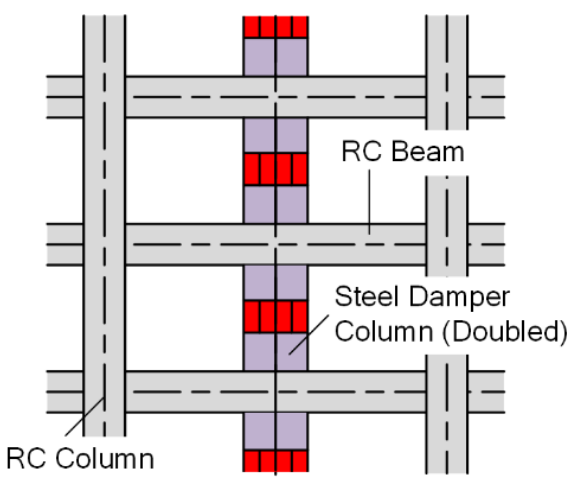

(b)

Figure 1: Steel damper column and its application to reinforced concrete (RC) frame structures. (a) Steel damper column [2]; and (b) RC frame with steel damper columns.

In this study, the strength balance of steel damper columns and surrounding beams in reinforced concrete frames with damper columns is investigated. First, the damper column strength ratio is defined on the basis of the rigid-perfectly plastic mechanical model. Next, a nonlinear dynamic analysis of frame models is conducted to investigate the influence of the damper column strength ratio on the nonlinear seismic response of $\mathrm{RC}$ frames with steel damper columns.

\section{DEFINITION OF DAMPER COLUMN STRENGTH RATIO}

Consider a RC frame with a damper column (Fig. 2). Here, $H_{i}$ denotes the height of level $i$ above ground level, and $h_{i}$ the height of the $i$ th story. For simplicity in discussions, three assumptions are made:

- All RC beams undergo rigid-perfectly plastic behaviour, and all RC columns are infinitely rigid and strong.

- All shear panels undergo rigid-perfectly plastic behaviour, and all elastic columns are infinitely rigid and strong.

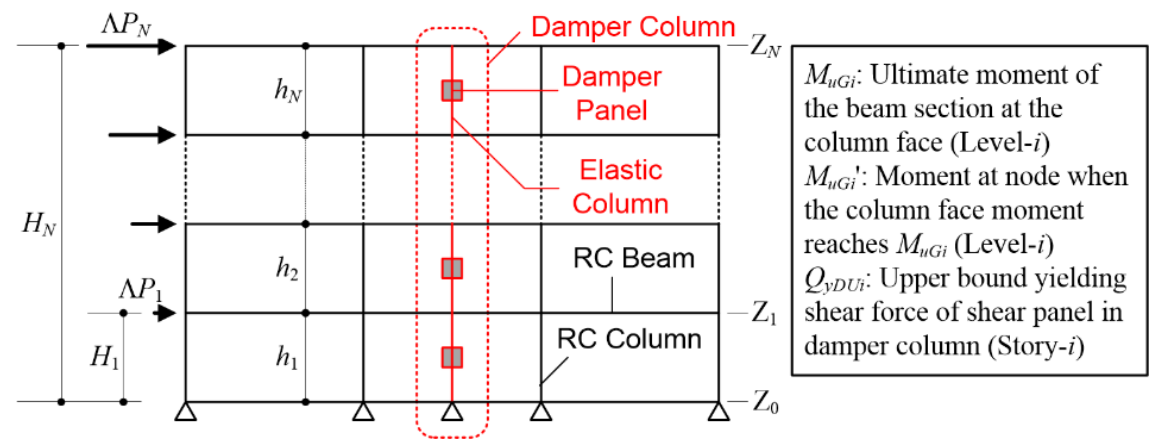

Figure 2: RC frame with damper column. 
- In the calculation of internal virtual work, the work done by each plastic hinge at a node is assumed to be the product of the moment $M_{u G i} i^{\prime}$ and the plastic rotation.

On the basis of these assumptions, we consider two collapse mechanisms (Fig. 3); here, $P_{i}$ denotes the assumed horizontal force at level $i, \theta_{p}$ the plastic rotation. Assuming all RC columns are infinitely rigid and strong, both mechanisms belong to the "whole collapse" class; moreover, for mechanism 1, all shear damper panels yield whereas, for mechanism 2, no shear damper panels yield. Let $\Lambda_{j}$ denote the collapse load factor for mechanism $j$; the external virtual work is calculated as

$$
\delta W_{O j}=\Lambda_{j}\left(\sum_{i=1}^{N} P_{i} H_{i}\right) \theta_{p} .
$$

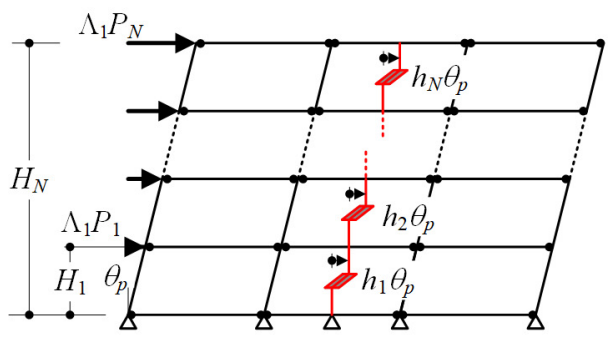

(a)

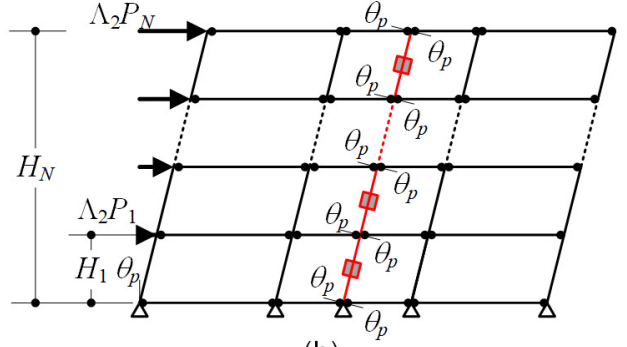

(b)

Figure 3: Collapse mechanism of RC frame with damper column. (a) Mechanism 1 (damper panel yields); and (b) Mechanism 2 (damper panel does NOT yield).

Next, the internal virtual work of mechanism $j, \delta W_{I j}$, is assumed to be the sum of the internal virtual work done by (a) the damper columns and the beam-end sections connected to the damper columns, $\delta W_{I D j}$, and (b) the other RC beam sections, $\delta W_{I F j}$. That is,

$$
\delta W_{I j}=\delta W_{I D j}+\delta W_{I F j} .
$$

In collapse mechanism 1, the internal virtual work $\delta W_{I D 1}$ is calculated by considering the virtual work done by the damper panel,

$$
\delta W_{I D 1}=\left(\sum_{i=1}^{N} Q_{y D U i} h_{i}\right) \theta_{p} .
$$

Similarly, in collapse mechanism 2, the internal virtual work $\delta W_{I D 2}$ is calculated considering the virtual work done by the beam-end sections connected to damper column,

$$
\delta W_{I D 2}=\left\{\sum_{i=0}^{N}\left(M_{u G L i}{ }^{\prime}+M_{u G R i}{ }^{\prime}\right)\right\} \theta_{p} .
$$


Following the principle of virtual work, the collapse load factor for mechanism $j, \Lambda_{j}$, is obtained by equating $\delta W_{O j}$, in eqn (1) and $\delta W_{I j}$, in eqn (2). The true collapse load factor $\Lambda$ is then the minimum of $\Lambda_{1}$ and $\Lambda_{2}$, and hence the true collapse mechanism of the given frame corresponds to $\Lambda$.

Here, for both mechanisms, the internal virtual work done by the other RC beam sections, denoted $\delta W_{I F 1}$ and $\delta W_{I F 2}$, are assumed that to be the same. In this instance, the relationship between the magnitudes of $\Lambda_{1}$ and $\Lambda_{2}$ is determined from that between $\delta W_{I D 1}$ and $\delta W_{I D 2}$. The strength ratio, $\alpha$, for the damper column is then defined as

$$
\alpha \equiv \frac{\delta W_{I D 1}}{\delta W_{I D 2}}=\sum_{i=1}^{N} Q_{y D U i} h_{i} /\left\{\sum_{i=0}^{N}\left(M_{u G L i}{ }^{\prime}+M_{u G R i}{ }^{\prime}\right)\right\} .
$$

If $\alpha$ is smaller (larger) than unity, collapse mechanism 1 (2) occurs. In discussing the strength balance of the damper column and surrounding RC beams, we chose for this study the strength ratio as a quantitative indicator.

\section{FRAME MODEL AND GROUND MOTION DATA}

Next, nonlinear dynamic analyses of various frame models were performed to investigate the influence of the strength ratio of the damper column on the nonlinear seismic response of reinforced concrete frames with steel damper columns.

\subsection{Frame model data}

\subsubsection{Simplified frame model}

Fig. 4 illustrates one of the simplified frame models considered. This frame model is based on the ten-story RC frame model presented in Mukoyama et al. [4]; the lower part of the frame Y2 (frame with damper columns, range: stories 2 to 5 ) is extracted for a simplified frame model. The floor masses of levels 1 to 3 are assumed equal, with $m_{1}=m_{2}=m_{3}=270$ $\mathrm{t}$, whereas the mass of level 4 is assumed to be $m_{4}=1620 \mathrm{t}$, which takes into account the mass of the upper floors. Young's modulus and the shear modulus of the concrete are assumed to be $E_{C}=2.52 \times 10^{4} \mathrm{MPa}$ and $G_{C}=1.08 \times 10^{4} \mathrm{MPa}$, respectively. Fig. 5 presents the envelope of the force-deformation relationship of the nonlinear flexural spring of RC members. The same modelling applied in Mukoyama et al. [4] is used in this study except for the RC columns; only stiffness degradation due to cracking is considered and no flexural yielding is considered. Fig. 6 shows the hysteresis rule of the members. The Muto hysteresis model [5] with one modification (Fig. 6(a)) is used to model the flexural spring in the RC members, whereas the hysteresis model proposed by Ono and Kaneko [6] (Fig. 6(b)) is used to model the shear behaviour of the damper columns taking into consideration the strainhardening behaviour.

Tables 1 and 2 list the properties of RC beams and columns used in the simplified model. In both tables, $b$ and $D$ denote the width and depth of the sections, respectively, $I, A_{S}$ and $A_{N}$ the moment of inertia, and the sectional area for shear and axial deformation, respectively, that takes into account the difference in concrete strength for each level. In addition, $M_{c}$ and $M_{y}$ denote the flexural cracking and yielding moments, respectively, and $\alpha_{y}$ denotes the secant stiffness degradation ratio at the yield point (Fig. 5). Extracted from a 10-story frame structure, our simplified frame model comprises beams for levels $Z_{0}$ and $Z_{4}$ corresponding to the boundary; therefore, the stiffness and strength of these beams are assumed to be $1 / 2$ that of the original model. 


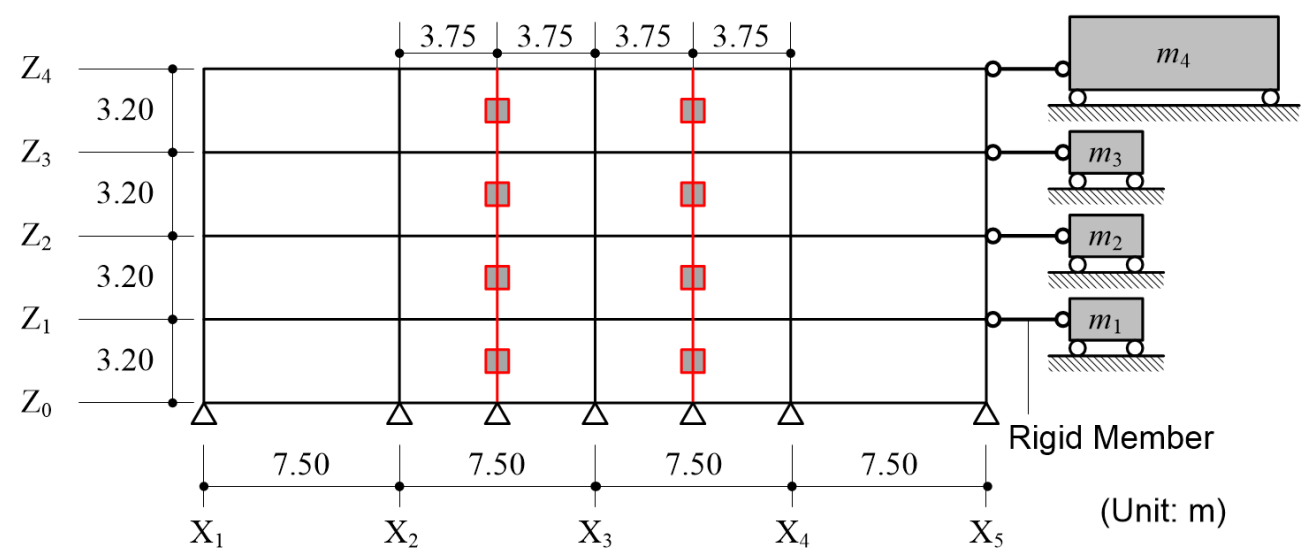

Figure 4: Simplified frame model.

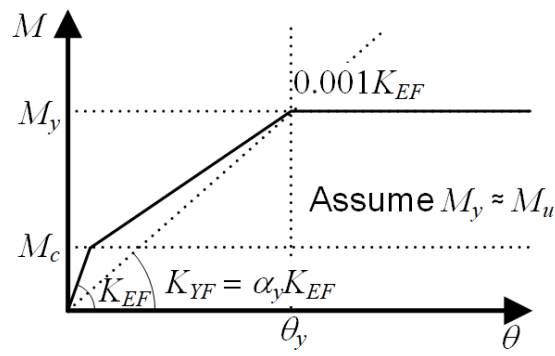

(a) RC Beam End

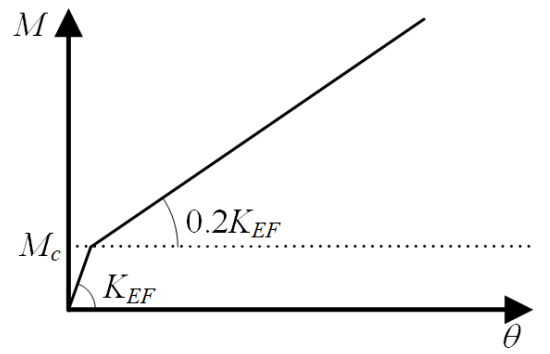

(b) RC Column End

Figure 5: Envelope of the force-deformation relationship of nonlinear flexural spring.

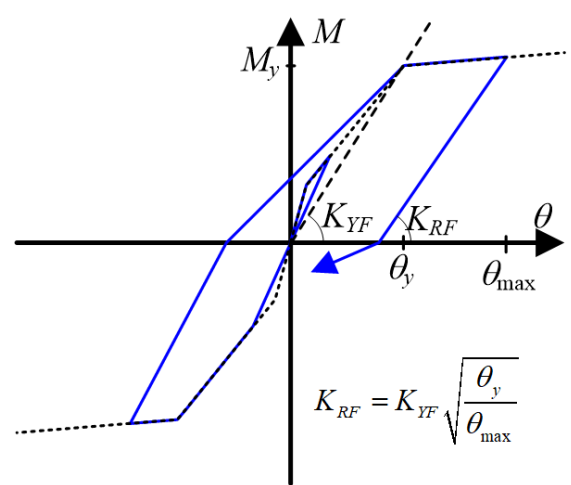

(a) Nonlinear Flexural Spring (RC Beam and Column)

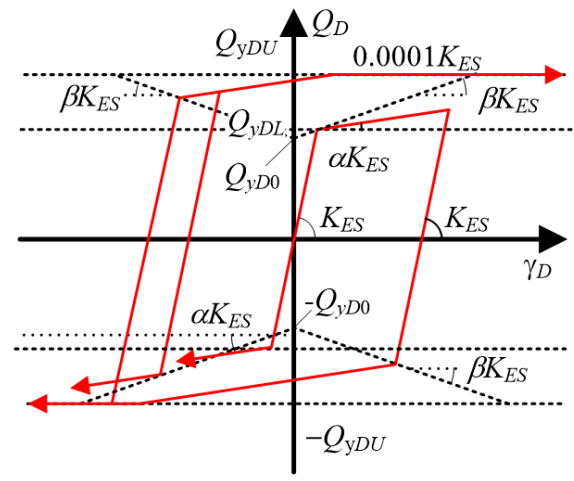

(b) Shear

(Damper Panel)

Figure 6: Hysteresis rules. 
Table 1: Properties of RC beams.

\begin{tabular}{|c|c|c|c|c|c|c|c|c|}
\hline Lv. & \multirow{2}{*}{$\begin{array}{c}b \\
(\mathrm{~mm})\end{array}$} & $\begin{array}{c}D \\
(\mathrm{~mm})\end{array}$ & $\begin{array}{c}I \\
\left(\mathrm{~m}^{4}\right)\end{array}$ & $\begin{array}{c}A_{S} \\
\left(\mathrm{~m}^{2}\right)\end{array}$ & $\begin{array}{c}M_{c} \\
(\mathrm{kNm})\end{array}$ & \multicolumn{2}{|c|}{$M_{y}$} & \multicolumn{2}{|c|}{$\alpha_{y}$} \\
\cline { 7 - 9 } & $(\mathrm{kNm})$ & Outer & Inner \\
\hline $\mathrm{Z}_{4}$ & 550 & 900 & 0.0179 & 0.1929 & 367.9 & 1103.7 & 0.3455 & 0.1303 \\
$\mathrm{Z}_{3}$ & 600 & 900 & 0.0376 & 0.4359 & 827.7 & 2483.2 & 0.3510 & 0.1228 \\
$\mathrm{Z}_{1}, \mathrm{Z}_{2}$ & 600 & 900 & 0.0376 & 0.4359 & 886.8 & 2660.4 & 0.3640 & 0.1228 \\
$\mathrm{Z}_{0}$ & 800 & 900 & 0.0243 & 0.3000 & 594.2 & 1782.6 & 0.3650 & 0.1228 \\
\hline
\end{tabular}

Table 2: Properties of RC columns.

\begin{tabular}{|c|c|c|c|c|c|c|c|}
\hline \multirow{2}{*}{ Level } & \multirow{2}{*}{$\begin{array}{c}b \\
(\mathrm{~mm})\end{array}$} & \multirow{2}{*}{$\begin{array}{c}D \\
(\mathrm{~mm})\end{array}$} & $\begin{array}{c}I \\
\left(\mathrm{~m}^{4}\right)\end{array}$ & \multirow{2}{*}{$\begin{array}{c}A_{S} \\
\left(\mathrm{~m}^{2}\right)\end{array}$} & \multirow{2}{*}{$\begin{array}{c}A_{N} \\
\left(\mathrm{~m}^{2}\right)\end{array}$} & \multicolumn{2}{|c|}{$M_{c}(\mathrm{kNm})$} \\
\cline { 6 - 8 } & 900 & 900 & 0.0547 & 0.6750 & 0.8100 & 696.5 & 995.2 \\
3 & 900 & 900 & 0.0547 & 0.6750 & 0.8100 & 746.3 & 1094.8 \\
3 & 900 & 900 & 0.0547 & 0.6750 & 0.8100 & 796.1 & 1194.3 \\
2 & 900 & 900 & 0.0547 & 0.6750 & 0.8100 & 845.9 & 1293.9 \\
\hline
\end{tabular}

Table 3 lists the properties of a steel damper column; $Q_{y D L}$ and $Q_{y D U}$ denote respectively the initial and the upper bound yield strength of the damper panel (Fig. 6(b)). In addition, $t_{p}$ denotes the thickness of the damper panel, $A_{S D}$ the sectional area for shear deformation of damper panel, and $H_{D 0}$ the height of damper panel. Young's modulus and the shear modulus for steel are set to $E_{S}=2.05 \times 10^{5} \mathrm{MPa}$ and $G_{S}=7.88 \times 10^{4} \mathrm{MPa}$, respectively. The initial normal yield stress of the steel used for damper panels is set to $205 \mathrm{MPa}$ whereas the nominal yield stress after appreciable cyclic loading is set to $300 \mathrm{MPa}$.

Table 3: Properties of steel damper column.

\begin{tabular}{|c|c|c|c|c|c|c|}
\hline Level & $\begin{array}{c}Q_{y D L} \\
(\mathrm{kN})\end{array}$ & $\begin{array}{c}Q_{y D U} \\
(\mathrm{kN})\end{array}$ & $\begin{array}{c}t_{p} \\
(\mathrm{~mm})\end{array}$ & $\begin{array}{c}A_{S D p} \\
\left(\mathrm{~m}^{2}\right)\end{array}$ & $\begin{array}{c}H_{D 0} \\
(\mathrm{~m})\end{array}$ & $\begin{array}{c}\text { Section of elastic column } \\
(\mathrm{mm} \times \mathrm{mm} \times \mathrm{mm} \times \mathrm{mm})\end{array}$ \\
\hline 4 & 1251 & 1831 & 9 & 0.0106 & 0.600 & $\mathrm{H}-600 \times 250 \times 16 \times 32 \times 2$ \\
1 to 3 & 1511 & 2211 & 9 & 0.0128 & 0.700 & $\mathrm{H}-700 \times 300 \times 16 \times 28 \times 2$ \\
\hline
\end{tabular}

The damping matrix is assumed to be proportional to the instantaneous stiffness matrix without a damper column. The damping ratio of the first elastic mode of the model without a damper column is assumed to be 0.05 ; its natural period without damper is $0.725 \mathrm{~s}$, whereas that with damper is $0.477 \mathrm{~s}$.

\subsubsection{Analysis parameters}

In this analysis, the structural parameter is the strength balance of the damper column and surround RC beams. The assumptions regarding yield strength of the beam sections connected to damper columns are described below.

Fig. 7 depicts the bending moment at the beam-end section connected to the damper columns. At the beam-end sections $\mathrm{A}_{1}$ and $\mathrm{B}_{2}$, the bending moment is assumed to be the yielding moment $M_{y G i}$. The equilibrium of the moment at node $\mathrm{C}$ is

$$
M_{G L i}{ }^{\prime}+M_{G R i}{ }^{\prime}=\frac{1}{2}\left(Q_{y D U i} h_{i}+Q_{y D U i+1} h_{i+1}\right)
$$


Assuming moment $M_{G L i}{ }^{\prime}$ equals $M_{G R i}{ }^{\prime}$, the moment at the beam-end sections $\mathrm{B}_{1}$ and $\mathrm{A}_{2}$ is

$$
M_{G L i}=M_{G R i}=\frac{1}{1+d L_{d} / L_{0}}\left\{\frac{1}{4}\left(Q_{y D U i} h_{i}+Q_{y D U i+1} h_{i+1}\right)-\frac{d L_{d}}{L_{0}} M_{y G i}\right\} .
$$

Note that for $i=0$, the value of $Q_{y D U i} h_{i}$ is set to zero. Similarly, the value of $Q_{y D U i+1} h_{i+1}$ is set to zero for $i=4$.

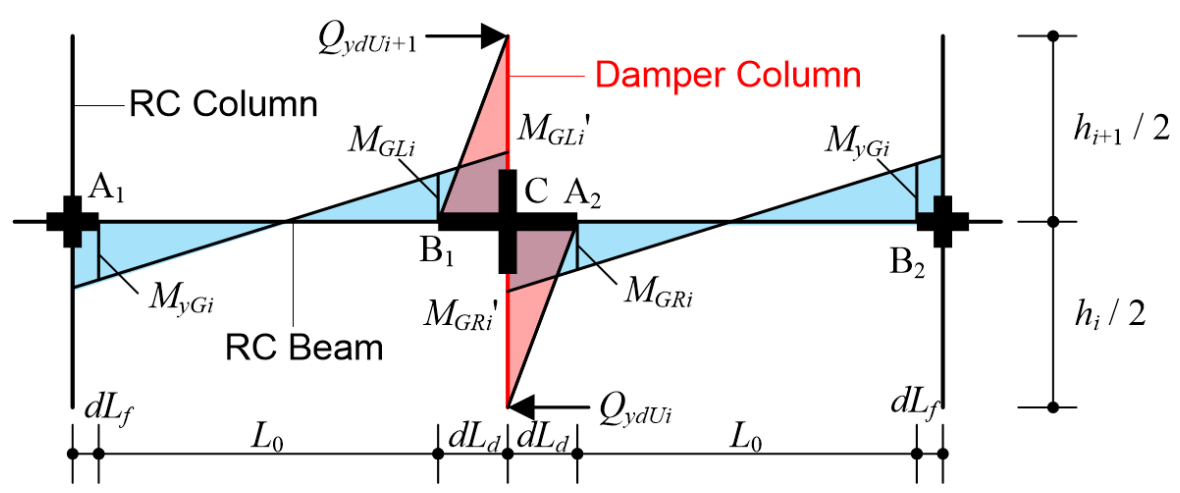

Figure 7: Bending moment at the beam-end sections connected to damper columns.

Given the above, the yield strength $M_{y}$ at the beam-end sections connected to damper columns are determined using beam-end strength ratio $\alpha_{G}\left(=M_{y} / M_{G L}\right)$; for $\alpha_{G}=1, M_{y}$ equals to $M_{G L}$.

Fig. 8 shows the assumed moment-deformation angle relationship of a flexural spring at the beam-end section connected to the damper column. The cracking moment $M_{c}$ and the secant stiffness degradation ratio at yielding $\alpha_{y}$ is set independent of $\alpha_{G}$ for simplicity. Therefore, the tangent stiffness degradation ratio after crack $\alpha_{1}$ is assumed to increase as $\alpha_{G}$ increases. Parameter $\alpha_{G}$ is set from 0.7 to 1.5 with step intervals of 0.1 . Table 4 lists the beamend strength ratio $\alpha_{G}$ and corresponding damper column strength ratio $\alpha$. For the calculation of $\alpha$, the ultimate moment of the beam section at the column face is assumed to be their yielding moment. As listed, the damper column strength ratio $\alpha$ decreases as $\alpha_{G}$ increases.

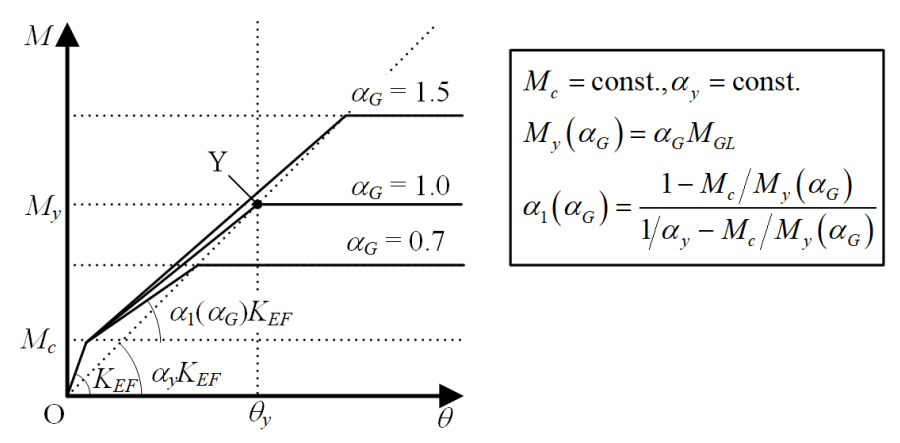

Figure 8: Assumed moment-deformation angle relationship of flexural spring at beamend section connected to damper column. 
Table 4: Beam-end strength ratio $\alpha_{G}$ and corresponding damper column strength ratio $\alpha$.

\begin{tabular}{c|ccccccccc}
\hline$\alpha_{G}$ & 0.7 & 0.8 & 0.9 & 1.0 & 1.1 & 1.2 & 1.3 & 1.4 & 1.5 \\
\hline$\alpha$ & 1.320 & 1.193 & 1.088 & 1.000 & 0.925 & 0.861 & 0.805 & 0.756 & 0.712 \\
\hline
\end{tabular}

\subsection{Ground motion data}

Ten artificial ground motions are generated. The target elastic spectrum with $5 \%$ critical damping (pseudo-acceleration spectrum ${ }_{p} S_{A}(T, 0.05)$, with $T$ denoting the natural period of the system) was determined from the Building Standard Law of Japan [7] applying type-2 soil conditions. Specifically,

$$
{ }_{p} S_{A}(T, 0.05)=\left\{\begin{array}{lll}
4.8+45 T \quad \mathrm{~m} / \mathrm{s}^{2} & T \leq 0.16 \mathrm{~s} \\
12.0 & 0.16 \mathrm{~s} \leq T \leq 0.864 \mathrm{~s} . \\
12.0(0.864 / T) & T>0.864 \mathrm{~s}
\end{array}\right.
$$

The phase angle is obtained as a uniform random value and the Jenning-type envelope function $e(t)$ proposed by the Building Centre of Japan [8]. Fig. 9 shows the pseudoacceleration spectrum and the total energy spectrum [9] of the artificial ground motions used in this study. The ground accelerations are scaled using a multiplicative factor $\lambda$ that is set between 0.5 and 1.0 .

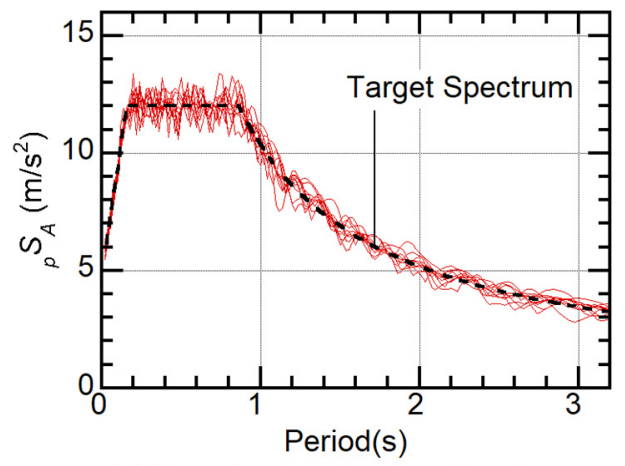

(a) Pseudo Acceleration Spectrum

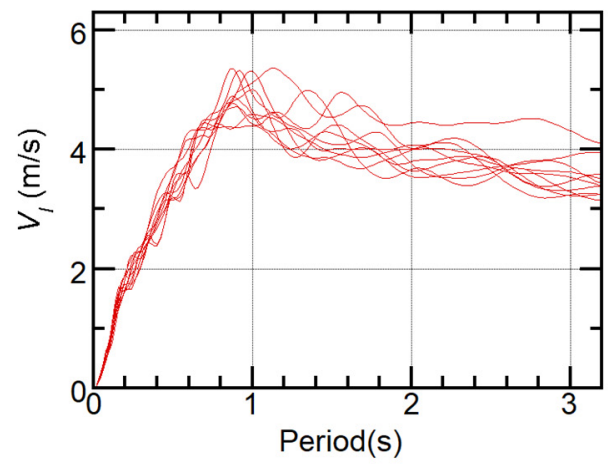

(b) Total Input Energy Spectrum

Figure 9: Elastic response spectra of artificial ground motions used in this study.

\section{ANALYSIS RESULTS AND DISCUSSIONS}

\subsection{Analysis results}

Averages of results obtained from the nonlinear dynamic analysis of the ten artificial ground motions were considered. Fig. 10 shows the relationship between the maximum of the whole deformation angle $R^{*}{ }_{\text {max }}$, defined as the peak horizontal displacement at level $\mathrm{Z}_{4}$ divided by the total height $H_{4}$ and the damper column strength ratio $\alpha$. The whole deformation angle 
$R^{*}{ }_{\max }$ increases as $\alpha$ increases, the variation being more noticeable for $\lambda=1.0$ (Fig. 10(b)) than with $\lambda=0.5$ (Fig. 10(a)).

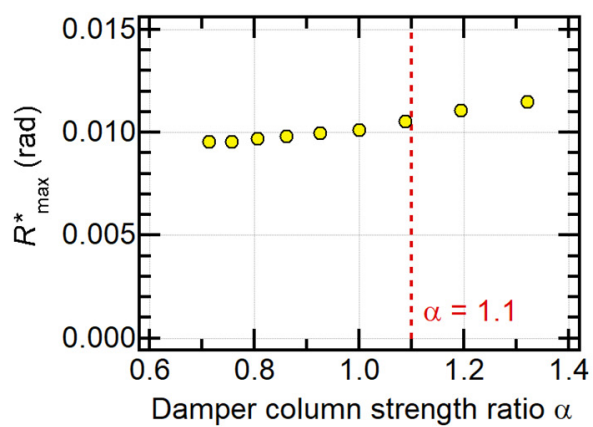

(a) $\lambda=0.5$

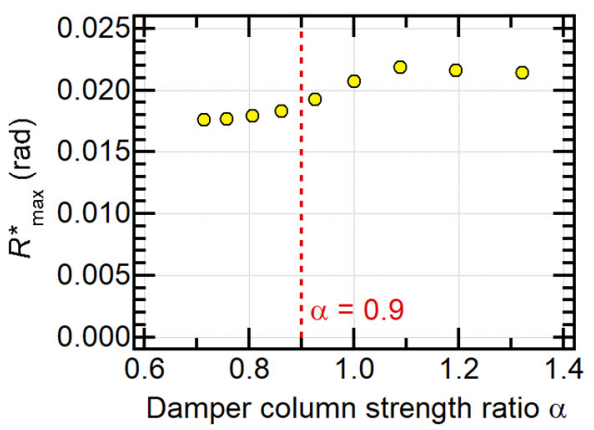

(b) $\lambda=1.0$

Figure 10: Whole deformation angle.

Fig. 11 shows the relationship between the total input energy $E_{I}$, cumulative strain energy (whole frame: $E_{S}, \mathrm{RC}$ frame: $E_{S f}$, steel damper columns: $E_{S d}$ ) and the damper column strength ratio $\alpha$. The variation in $E_{I}$ and $E_{S}$ is not noticeable. However, $E_{S f}$ increases whereas $E_{S d}$ decreases, as $\alpha$ increases. For $\lambda=0.5$ (Fig. 11(a)), $E_{S f}$ exceeds $E_{S d}$ when $\alpha$ is larger than 1.1, whereas for $\lambda=1.0$ (Fig. 11(b)), $E_{S f}$ exceeds $E_{S d}$ when $\alpha$ is larger than 0.9. This implies that the effectiveness of steel damper columns is strongly related to the damper column strength ratio $\alpha$; the steel damper column is more efficient at energy dissipation if $\alpha$ is small.

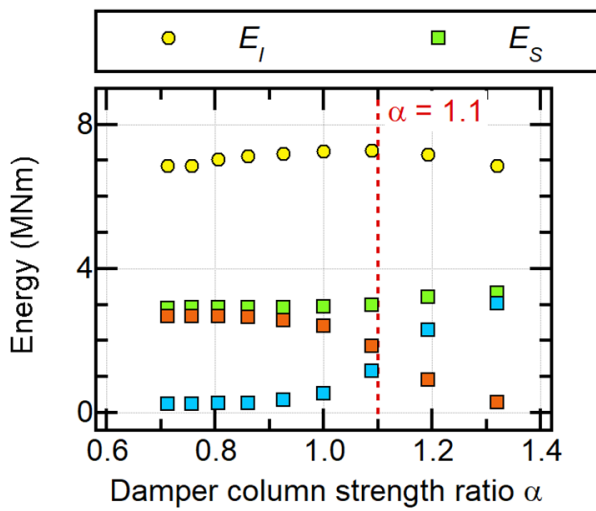

(a) $\lambda=0.5$

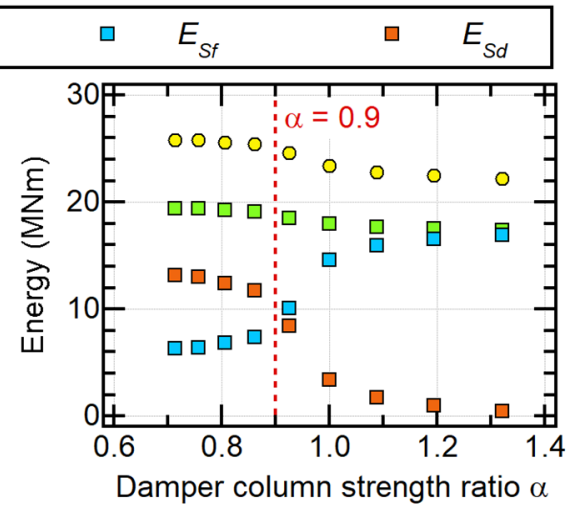

(b) $\lambda=1.0$

Figure 11: Total input energy and cumulative strain energy.

In summary, the damper column strength ratio $\alpha$ is suitable in discussing the strength balance of the damper columns and surrounding RC beams; for a better effectiveness of steel damper columns, $\alpha$ should be low in value. Based on our numerical analysis results, $\alpha$ should not exceed 0.9 when the expected whole deformation angle is close to $0.02 \mathrm{rad}$. 


\subsection{Discussion}

As described in Section 2, the difference in the two collapse mechanisms is the yielding of the beam-end connected to damper column. Therefore, our discussion begins from the plastic rotation of the beam-end connected to damper columns. Fig. 12 depicts the location of the beam-end investigated herein and a definition of the plastic rotation angle. Here, $\theta_{p \max }$ is the peak plastic rotation angle; when $\theta_{\max }$ is less than $\theta_{y}, \theta_{p \max }$ is zero (no yielding occurs).

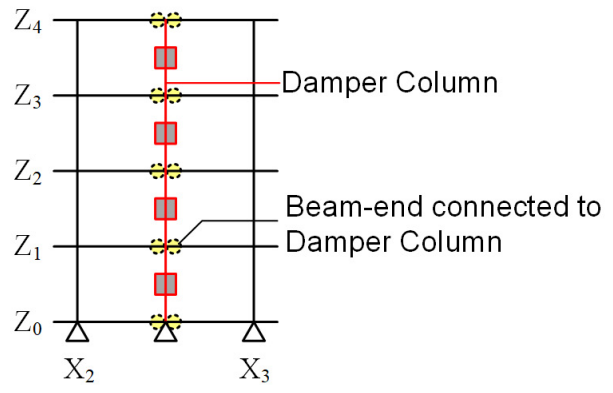

(a) Beam-end connected to Damper Column

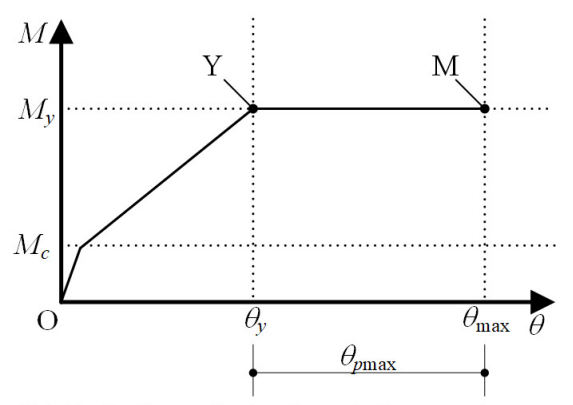

(b) Definition of plastic rotation angle

Figure 12: Plastic rotation at beam-end connected to damper column.

Fig. 13 shows the relationship between the peak plastic rotation at beam-ends connected to damper columns $\theta_{p \max }$ at each level and the damper column strength ratio $\alpha$. As expected, $\theta_{p \max }$ increases as $\alpha$ increases. For $\lambda=0.5$ (Fig. 13(a)), $\theta_{p \max }$ is almost zero when $\alpha$ is less than 0.9. A similar observation holds for $\lambda=1.0$ (Fig. 13(b)). This implies that the behaviour of the simplified frame model is similar to collapse mechanism 1 (damper panel yield) when $\alpha$ is small.

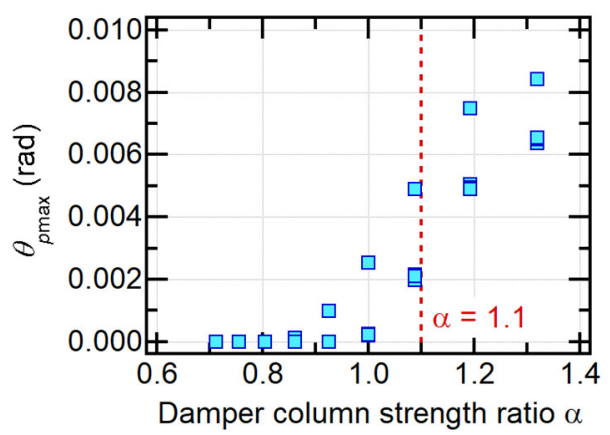

(a) $\lambda=0.5$

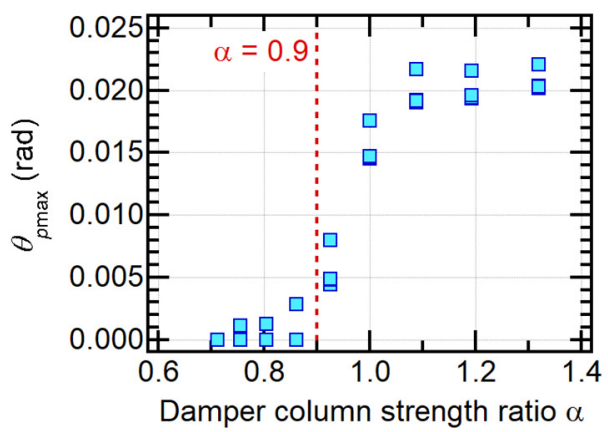

(b) $\lambda=1.0$

Figure 13: Peak plastic rotation angle at beam-ends connected to damper column.

Next, focusing on the behaviour of the damper panel, Fig. 14 presents the relationship between the peak shear strain of the damper panel in each damper column $\gamma_{D \max i}$ and the damper column strength ratio $\alpha$. As expected, $\gamma_{D \max i}$ is large and stable when $\alpha$ is small. For 
$\lambda=0.5$ (see Fig. 14(a)), the peak shear strain $\gamma_{D \max i}$ is stable if $\alpha$ is less than 1.1, whereas if $\alpha$ is larger than 1.1 the strain decreases rapidly as $\alpha$ increases. A similar observation holds if $\lambda$ $=1.0$ (Fig. 14(b)). The peak shear strain $\gamma_{D \max i}$ decreases rapidly as $\alpha$ increases if $\alpha$ is larger than 0.9. Note that the peak shear strain $\gamma_{D \max i}$ reaches $5 \%$ and more if $\alpha$ is less than 0.9 . This implies that the condition of the damper panel is close to the ultimate stage [2]. Therefore, $\alpha$ $=0.9$ seems suitable in eliciting full performance from the damper columns.

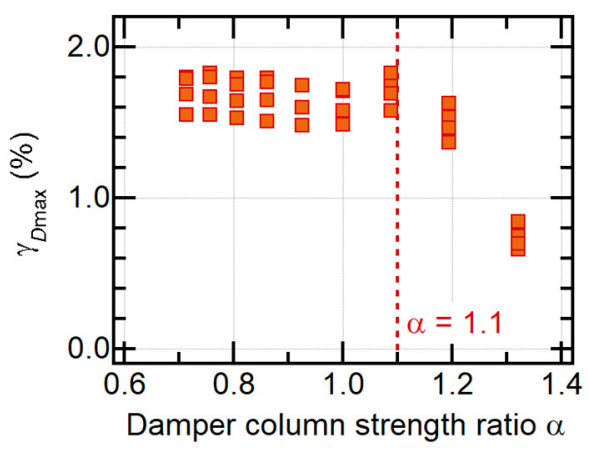

(a) $\lambda=0.5$

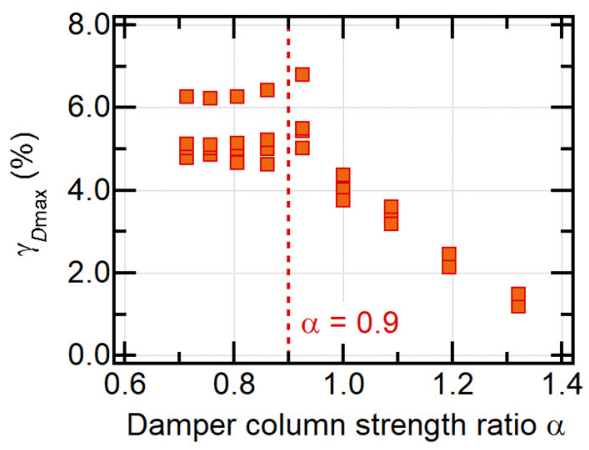

(b) $\lambda=1.0$

Figure 14: Peak shear strain of damper panel.

In summary, the effectiveness of steel damper columns is pronounced if $\alpha$ is less than 0.9 . The mechanism underlying the behaviour of the RC frame with a damper column is collapse mechanism 1 (Fig. 3(a)) if $\alpha$ is less than 0.9. In this instance, the deformation of damper panels is pronounced, and the energy absorption of the damper panels maximized. Note that in theory (see Section 2), the boundary between the two collapse mechanisms occurs at $\alpha=$ 1. However, the nonlinear dynamic analysis results indicate that a reasonable criterion should be 0.9. This arises from the variation in moment distribution in the damper column arising from the influence of higher mode. Therefore, some safety factor is needed for the yielding moment at the beam-end section connected to the damper column. Based on the results obtained, the recommended value for the safety factor is $\alpha_{G}=1.2(\alpha=0.861$, Table 4).

\section{CONCLUSIONS}

The strength balance of steel damper columns and surrounding beams in reinforced concrete frame with a damper column was investigated. The main contribution and results of this study are the following:

- The damper column strength ratio $\alpha$ proposed, eqn (5), is a potential index to discuss the strength balance of steel damper columns and surrounding beams.

- Based on the numerical analysis results presented, the damper column strength ratio $\alpha$ should not exceed 0.9 when the expected whole deformation angle is close to $0.02 \mathrm{rad}$.

\section{ACKNOWLEDGEMENTS}

The authors thank the financial support from JFE Civil Engineering and Construction Corp. Valuable comments from Chizuru Irie and Mitsuhide Yoshinaga, JFE Civil Engineering and Construction Corp. are also appreciated. The original frame model data for the reinforced concrete building was provided from Riho Mukoyama, a graduate student of Chiba Institute 
of Technology. We thank Richard Haase, PhD, from Edanz Group (https://en-authorservices.edanz.com/ac) for editing a draft of this manuscript.

\section{REFERENCES}

[1] Katayama, T., Ito, S., Kamura, H., Ueki, T. \& Okamoto, H., Experimental study on hysteretic damper with low yield strength steel under dynamic loading. Proceedings of the 12th World Conference on Earthquake Engineering, Paper No. 1020, 2000.

[2] JFE Civil Engineering \& Construction Corp., JFE no Seishin-mabashira, JFE no Seishin-panel (Vibration control column and panel product by JFE). 2019. www.jfecivil.com/pdf/catalog/vibration_control_column.pdf. Accessed on: 31 Mar. 2021 (in Japanese).

[3] Nakashima, M., Strain-hardening behaviour of shear panels made of low-yield steel 1: Test. Journal of Structural Engineering, 121(12), pp. 1742-1749, 1995.

[4] Mukoyama, R., Fujii, K., Irie, C., Tobari, R., Yoshinaga, M. \& Miyagawa, K., Displacement-controlled seismic design method of reinforced concrete frame with steel damper column. Proceedings of the 17th World Conference on Earthquake Engineering, Paper No. 2g-0143, 2020.

[5] Muto, K., Hisada, T., Tsugawa, T. \& Bessho, S., Earthquake resistant design of a 20 story reinforced concrete buildings. Proceedings of the Fifth World Conference on Earthquake Engineering, pp. 1960-1969, 1974.

[6] Ono, Y. \& Kaneko, H., Constitutive rules of the steel damper and source code for the analysis program. Passive Control Symposium 2001, Structural Engineering Research Center, Tokyo Institute of Technology, pp. 163-170, 2001 (in Japanese).

[7] BCJ, The Building Standard Law of Japan on CD-ROM. The Building Center of Japan, 2016.

[8] Otani, S., Japanese seismic design of high-rise reinforced concrete buildings - An example of performance-based design code and state of practices. Proceedings of the 13th World Conference on Earthquake Engineering, Paper No. 5010, Vancouver, Canada, 2004.

[9] Akiyama, H., Earthquake-Resistant Limit-State Design for Buildings, University of Tokyo Press: Tokyo, Japan, 1985.

[10] Akiyama, H., Earthquake-Resistant Design Method for Buildings Based on Energy Balance, Gihodo Shuppan, 230 p., 1999 (in Japanese). 